\title{
Isolation and characterization of pristimerin as the antiplasmodial and antileishmanial agent of Maytenus senegalensis (Lam.) Exell.
}

\author{
Sami A. Khalid, ${ }^{\mathrm{a}^{*}}$ Gerda M. Friedrichsen, ${ }^{\mathrm{b}}$ Soren B. Christensen, \\ Ahmed El Tahir, ${ }^{c}$ and Gwiria M. Sattic \\ ${ }^{a}$ Department of Pharmacognosy, Faculty of Pharmacy, University of Khartoum, P.O.Box 1996, \\ Khartoum, Sudan \\ ${ }^{b}$ Department of Medicinal Chemistry, Natural Products Research, The Danish University of \\ Pharmaceutical Sciences, Universitetparken, DK-2100 Copenhagen, Denmark \\ ${ }^{c}$ Department of Biochemistry, Faculty of Medicine, University of Khartoum, \\ P.O.Box 102, Khartoum, Sudan \\ E-mail: khalidseek@hotmail.com
}

Dedicated to Professor Berhanu M. Abegaz on his $60^{\text {th }}$ Birthday

\begin{abstract}
Bioactivity directed fractionation of the chloroform extract of the root bark of Maytenus senegalensis resulted in the isolation and characterization of the quinonemethide triterpene, (20a)-3-hydroxy-2-oxo-24-nor-friedela-1(10),3,5,7-tetraen-carboxylic acid-(29)-methylester (pristimerin). The structure was elucidated by spectroscopic techniques. The in vitro antiplasmodial activity of the isolated compound against chloroquine-resistant strain (Dd2) of Plasmodium falciparum was $\mathrm{IC}_{50}=0.5 \mu \mathrm{g} / \mathrm{ml}$ and its in vitro antileishmanial activity performed on promostigotes of Leishmania major was $\mathrm{IC}_{50}=6.8 \pm 0.8 \mu \mathrm{g} / \mathrm{ml}$ while the cytotoxicity on lymphocyte proliferation model was detected at $\mathrm{IC}_{50}=6.8 \pm 0.8 \mu \mathrm{g} / \mathrm{ml}$.
\end{abstract}

Keywords: Maytenus senegalensis, Celasterceae, root bark, chloroform extract, quininemethide triterpenes, pristimerin, traditional medicine, malaria, antiplasmodil, leishmania, antileshmanial, cytotoxicity

\section{Introduction}

The decoction of the root bark of Maytenus senegalensis (Celasterceae) is very widely used in Sudan and other African countries in the traditional medicine to treat malaria. The genus Maytenus is rich source of quinonemethide triterpenes and these compounds seem to have a variety of biological activities such as antimicrobial, cytotoxic and antimalarial properties. ${ }^{1}$ 
Bioactivity directed fractionation of the chloroform extract resulted in isolation of a quinonemethide pentacyclic triterpene of friedelane type, which was identified by spectroscopic techniques as (20 )-3-hydroxy-2-oxo-24-nor-friedela-1(10),3,5,7-tetraen-carboxylic acid-(29)methylester. This compound has given the trivial name pristimerin (1) in the literature. ${ }^{2}$

\section{Results and Discussion}

Fractionation of the concentrated crude chloroform extract of the root bark of Maytenus senegalensis by column chromatography over silica gel resulted in 15 fractions. All fractions were monitored for antimalarial and antileishmanial activities. The second fraction (240 mg) exhibited the highest antimalarial $\left(\mathrm{IC}_{50}=1.6 \mu \mathrm{g} / \mathrm{ml}\right)$ and antileishmanial $\left(\mathrm{IC}_{50}=6.3 \mu \mathrm{g} / \mathrm{ml}\right)$ activities and was further subjected to reverse phase column chromatography (Rp-18) to yield 6 $\mathrm{mg}$ of pure orange crystals. The melting point obtained $\left(219-12{ }^{\circ} \mathrm{C}\right)$ was identical with the literature data. ${ }^{2}$

The UV spectrum was indicative of a peri-hydroxy-ortho-naphthoquinone partial structure. The spectrum exhibited two prominent absorption bands at 425 and $255 \mathrm{~nm}$, with a shoulder at 335-340 $\mathrm{nm}$. The IR spectrum showed bands for chelated hydroxyl $\left(3370 \mathrm{~cm}^{-1}\right)$, ester carbonyl $\left(1735 \mathrm{~cm}^{-1}\right)$ and the conjugated carbonyl of the quinonemethide system $\left(1600 \mathrm{~cm}^{-1}\right)$. Both the UV and IR spectral data are in full agreement with reported values. ${ }^{2}$

${ }^{1} \mathrm{H}-\mathrm{NMR}$ spectrum was characterized by the presence of two main groups of resonances, one in the olefinic/aromatic region and the other in the aliphatic region. The spectrum also revealed resonances of a carbomethoxy and vinyl methyl groups. The presence of six methyl signals $(3 \mathrm{H}$ each) and one acetoxy in the proton spectrum is indicative of a pentacyclic triterpene of a friedelane type. ${ }^{3}$ The unsaturated region showed a very distinctive pattern attributable to a quinonoid moiety. $\mathrm{H}-1$ has a long range coupling to $\mathrm{H}-6$ and appeared as a doublet $(\mathrm{J}=1.4 \mathrm{~Hz})$ while $\mathrm{H}-6$ couple to $\mathrm{H}-7(\mathrm{~J}=7.1 \mathrm{~Hz})$ and to $\mathrm{H}-1$, producing a double doublet. The vicinal coupling between H-6 and H-7 resulted in another doublet $(\mathrm{J}=7.1 \mathrm{~Hz})$ associated with the later proton. Table 1 displays the assignments of the proton signals.

${ }^{13} \mathrm{C}-\mathrm{NMR}$ spectrum (Table 1) revealed the presence of 30 carbons. The DEPT-spectrum exhibited seven methylenes which allowed the following assignments: 33.6 (C-11), 29.7 (C-12), 28.7 (C-15), 36.4 (C-16), 30.9 (C-19), 29.9 (C-21) and 34.8 ppm (C-22).

More rigorous analysis was achieved by 2D 1H-1H COSY spectrum. This experiment revealed the vicinal coupling between $\mathrm{H}-6$ and $\mathrm{H}-7$ and the long range coupling between $\mathrm{H}-1$ and H-6. However, this experiment provided no safe assignment of the signals in the aliphatic region. Therefore, HECTOR-spectrum was made to provide the stated assignments. These assignments were in full agreement with published data. 


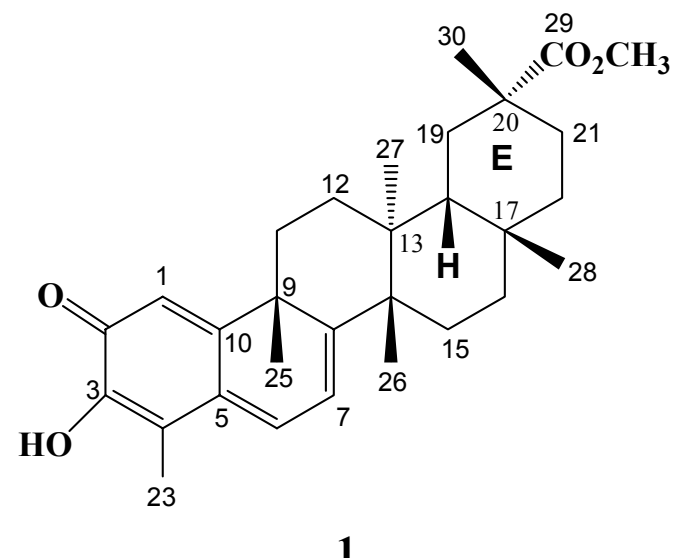

Table 1. ${ }^{1} \mathrm{H}(300 \mathrm{MHz})$ and ${ }^{13} \mathrm{C}(75 \mathrm{MHz})$ NMR data of $\mathbf{1}\left(\right.$ in $\left.\mathrm{CD}_{2} \mathrm{Cl}_{2}\right)$

\begin{tabular}{|c|c|c|c|}
\hline Assignment & ${ }^{1} \mathrm{H}(J$ in $\mathrm{Hz})$ & Carbon & $\begin{array}{c}{ }^{13} \mathrm{C} \\
\text { Observed } \\
\text { values }\end{array}$ \\
\hline \multirow{2}{*}{$\mathrm{H}-1$} & 6.56 & $\mathrm{C}-1$ & 119.8 \\
\hline & $d, J=1.4 \mathrm{~Hz}$ & $\mathrm{C}-2$ & 178.6 \\
\hline \multirow{2}{*}{ H-6 } & 7.04 & $\mathrm{C}-3$ & 146.3 \\
\hline & $d d, J=7.1 \mathrm{~Hz} \& 1.4 \mathrm{~Hz}$ & $\mathrm{C}-4$ & 117.4 \\
\hline \multirow{2}{*}{$\mathrm{H}-7$} & 6.36 & C-5 & 127.6 \\
\hline & $d, J=7.1 \mathrm{~Hz}$ & C-6 & 134.4 \\
\hline \multirow{2}{*}{$H-19 \alpha$} & 2.42 & C-7 & 118.3 \\
\hline & brd, $J=16 \mathrm{~Hz}$ & C-8 & 170.4 \\
\hline \multirow{2}{*}{ Me-23 } & 2.17 & C-9 & 43.0 \\
\hline & $S$ & $\mathrm{C}-10$ & 165.1 \\
\hline \multirow{2}{*}{ Me-25 } & 1.45 & C-11 & 33.6 \\
\hline & $S$ & C-12 & 29.7 \\
\hline \multirow{2}{*}{ Me-26 } & 1.26 & $\mathrm{C}-13$ & 39.5 \\
\hline & $s$ & C-14 & 45.1 \\
\hline \multirow{2}{*}{ Me-27 } & 0.53 & $\mathrm{C}-15$ & 28.7 \\
\hline & $S$ & $\mathrm{C}-16$ & 36.4 \\
\hline \multirow{2}{*}{$\mathrm{Me}-28$} & 1.09 & $\mathrm{C}-17$ & 30.9 \\
\hline & $S$ & $\mathrm{C}-18$ & 44.4 \\
\hline \multirow{2}{*}{ Me-30 } & 1.17 & C-19 & 30.9 \\
\hline & $S$ & $\mathrm{C}-20$ & 40.5 \\
\hline \multirow{10}{*}{$\mathrm{OMe}$} & 3.55 & C-21 & 29.9 \\
\hline & $S$ & C-22 & 34.8 \\
\hline & & C-23 & 10.3 \\
\hline & & C-24 & 38.3 \\
\hline & & C-25 & 21.7 \\
\hline & & C-26 & 18.4 \\
\hline & & C-27 & 31.7 \\
\hline & & C-28 & 179.1 \\
\hline & & C-29 & 32.7 \\
\hline & & $\mathrm{OMe}$ & 51.7 \\
\hline
\end{tabular}


The electron-impact mass spectrum (EI-MS) of compound 1 confirmed the molecular weight of 464 , corresponding to the formula $\mathrm{C}_{30} \mathrm{H}_{40} \mathrm{O}_{4}$. The molecular ion undergoes major fragmentations at the $\mathrm{C} / \mathrm{D}$ ring junction with hydrogen transfers occurring to provide four intense ions at $\mathrm{m} / \mathrm{z} 201$ (2), m/z 202 (3), m/z 267 (4) and m/z 203 (5). The first peak might be the result of a $\beta$-cleavage producing a tropylium ion $\left(\mathrm{C}_{13} \mathrm{H}_{13} \mathrm{O}_{2}\right)$ by engulfing one of the methylenes in the unsaturated ring. ${ }^{5}$ The molecular peaks at $\mathrm{m} / \mathrm{z} 267$ and 203 could be associated with fragment 4 and 5 respectively, which are usually related to the freidelane series of triterpenes (Scheme 1). A similar fragment was previously obtained from the fragmentation of tingenone which is structurally related to pristimerin. ${ }^{2}$

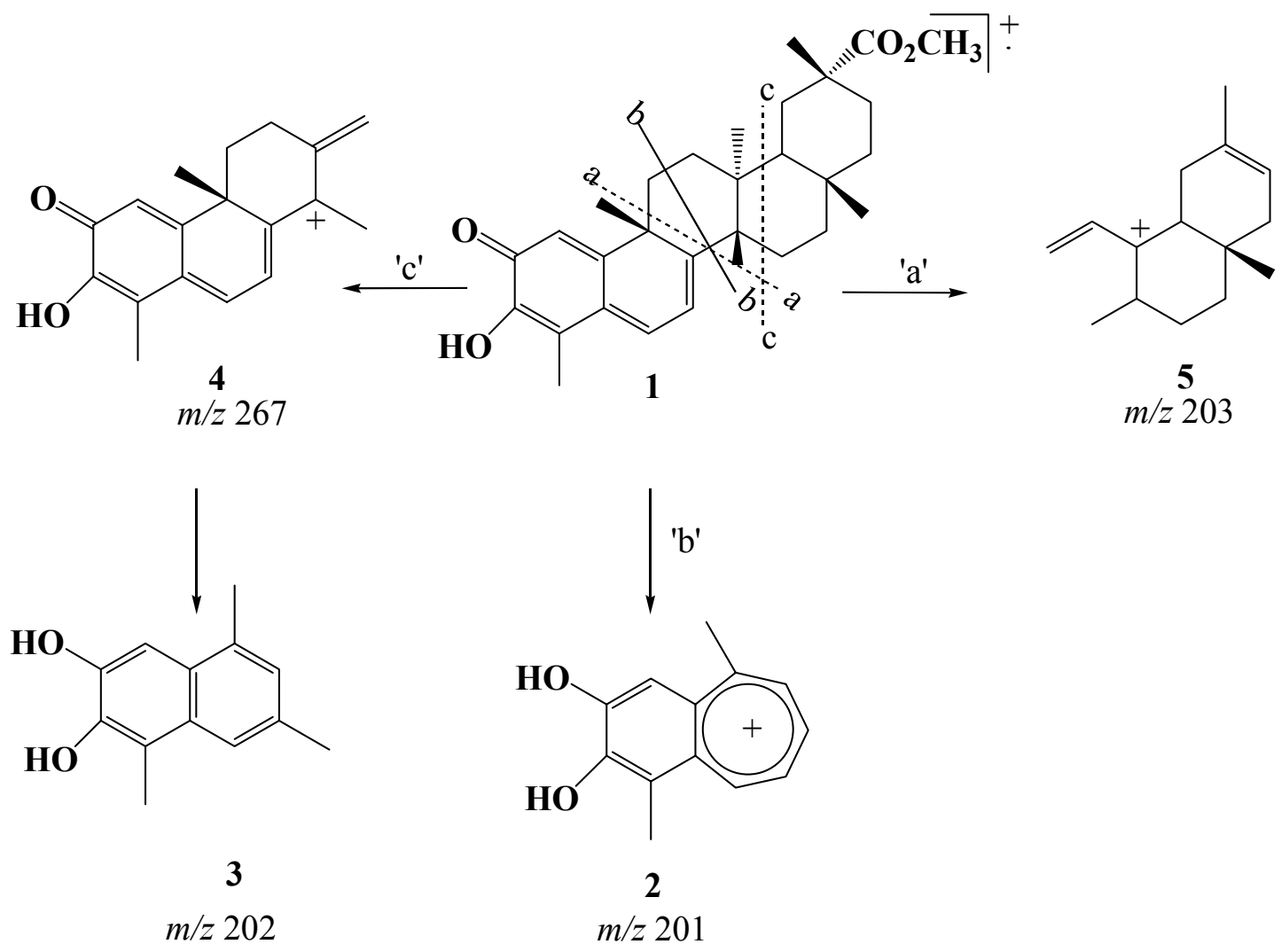

Scheme 1. Possible fragmentation of 1.

The isolated compound 1 exhibited promising antiplasmodial activity $\left(\mathrm{IC}_{50}=0.5 \mu \mathrm{g} / \mathrm{ml}\right)$ in vitro against chloroquine-resistant strain (Dd2) of Plasmodium falciparum and showed much less antileishmanial activity $\left(\mathrm{IC}_{50}=6.8 \pm 0.8 \mu \mathrm{g} / \mathrm{ml}\right)$ in vitro when performed on the promostigotes of the WHO reference strain of Leishmania major. The cytotoxicity of this compound was detected at $\mathrm{IC}_{50}=6.8 \pm 0.8 \mu \mathrm{g} / \mathrm{ml}$ when tested on lymphocyte proliferation model. 


\section{Experimental Section}

Plant material. Maytenus senegalensis (Lam.) Exell. was collected in the eastern region of Sudan. Herbarium specimen has been deposited in the Department of Pharmacognosy, Faculty of Pharmacy, University of Khartoum. The root bark $(300 \mathrm{~g})$ was extracted with chloroform and the concentrated extract $(6.5 \mathrm{~g})$ was subjected to column chromatography (silica gel 60, 0063-0.200 $\mathrm{mm}$ ). Elution with petroleum ether $\left(80-100^{\circ}\right)$ with increasing amount of ethyl acetate (from 0 to $100 \%$ ) then ethyl acetate with increasing amount of ethanol (from 0 to $100 \%$ ) yielded 15 fractions. All fractions were monitored for antiplasmodial and antileishmanial activities. The most bioactive fraction $(240 \mathrm{mg}$ ) was further fractionated by reverse phase (RP-18) medium pressure column chromatography using methanol/water (from $70 \%$ to $100 \%$ ) to provide orange powder which was eventually yielded orange crystals $(21 \mathrm{mg})$ of compound $\mathbf{1}$.

General Procedures. Thin layer chromatography was performed on normal phase Merck silica gel $60 \mathrm{~F}_{254}$ and Merck DC-Aluminium sheets $(5 \times 7.5 \mathrm{~cm})$. For reverse phase chromatography TLC Merck DC-Fertigplatten $(5 \times 10 \mathrm{~cm})$ with RP-18 $\mathrm{F}_{254}$ were used. MS was recorded on a JEOL AX505 W mass spectrometer. ${ }^{1} \mathrm{H}$ and ${ }^{13} \mathrm{C}$ NMR were recorded on Varian Gemini 300 spectrometer with TMS as internal standard.

In vitro antiparasitic and cytotoxic activity. The in vitro antipalasmodial assay was carried against the chloroquine-resistant strain (Dd2) of Plasmodium falciparum and the in vitro antileishmanial assay was performed on the promastigotes of a WHO reference vaccine strain of Leishmania major while the cytotoxicity assay was performed by measuring the inhibition of human peripheral blood lymphocyte ability of perforation when stimulated by the mitogen phytohaemagglutinin (PHA test). All these assays were performed as described earlier. ${ }^{6,7}$

\section{References}

1. Jellr, A. H.; Silva, D. H. S.; Liao, L. M.; Bolzani, V. S.; Furlan, M. Phytochemistry 2004, 65, 1977.

2. Gunatilaka, A. A. L. In Progress in the Chemistry of Organic Natural Products. 67 Herz, W.; Kirby, W. G.; Moore, R. E.; Steglich, W.; Tamm, C.; Eds., Springer- Verlag: Wien, 1996; pp 1- 123.

3. Gunatilaka, A. A. L.; Fernando, C.; Kikuchi, T.; Tezuka, Y. Magn. Reson. Chem. 1989, 27, 803.

4. Nakanishi, K. Y.; Takahashi, A.; Budzikiewicz, H. J. Org. Chem. 1965, 30, 1729.

5. Yamaguchi, K. Spectral Data of Natural Products. $1^{\text {st }}$ Edn. Elsevier: Amsterdam, 1970; p 150. 
6. El Tahir, A.; Ibrahim A.; Satti, G. M. H.; Theander, T. G.; Kharazmi, A.; Khalid, S. A.; Phytotherapy Research, 1998, 12, 576.

7. Khalid, S. A.; Friedrichsen, G. M.; Kharazmi, A.; Theander, T.; Christensen, S. B.; Olsen, C. E. Phytochemistry, 1998, 49, 1769. 